\title{
Interaction mechanism of collagen peptides with four phenolic compounds in the ethanol-water solution
}

\author{
Xian Liu' ${ }^{1,2}$, Xia Li ${ }^{1,2}$, Zhangjun Huang ${ }^{1,2}$, Xuepin Liao ${ }^{1,2,3^{*}}$ and Bi Shi ${ }^{1,2,3}$
}

\begin{abstract}
This study demonstrated the interaction mechanism of collagen peptides (CPs) with 4-ethylphenol (4-EP), phenol, guaiacol, and 4-ethylguaiacol (4-EG) in the ethanol-water solution. The ultraviolet visible spectroscopy, zeta potential tests and hydrogen nuclear magnetic spectroscopy manifested that CPs interacted with the phenolic compounds. Meanwhile, Isothermal titration calorimetry determination indicated that the CPs was hydrogen bonded with 4-EP in $52 \%(V / V)$ ethanol-water solution, while the hydrophobic forces played a major role in the interaction of CPs with guaiacol and 4-EG, respectively. Moreover, hydrogen and hydrophobic bonds were involved in the interaction between CPs and phenol. Finally, Head Space-solid Phase Microextraction Gas Chromatography Mass Spectrometry analysis indicated that the content of phenolic compounds in model solution efficiently decreased with the presence of CPs. In the real liquor, it was found that the content of volatile compounds (including phenolic compounds) was obviously decreased after CPs added.
\end{abstract}

Keywords: Ethanol-water solution, Collagen peptides, Phenolic compounds, Interaction mechanism, Volatile compounds, Liquor

\section{Introduction}

Chinese liquor (baijiu) is distilled from the solid fermentation of wheat, sorghum, corn, rice, and glutinous rice, and the history of it dated back to 2000 years ago [1]. According to the geographical division of raw materials, different starters and brewing technologies, Chinese liquor could be classified into strong-aroma types, saucearoma types, light-aroma types, rice-aroma types, tearoma types, feng-aroma types, herbal-aroma types, mixed-aroma types, chi-aroma types, fuyu-aroma types, sesame-aroma types, and laobaigan-aroma types $[2,3]$.

The flavor and taste of baijiu are substantially determined by its trace chemical components [4]. Over the past few decades, with the development of detection

\footnotetext{
* Correspondence: xpliao@scu.edu.cn

'Department of Biomass Science and Engineering, Sichuan University,

610065 Chengdu, China

${ }^{2}$ The Key Laboratory of Leather Chemistry and Engineering of Ministry of

Education, Sichuan University, 610065 Chengdu, China

Full list of author information is available at the end of the article
}

technology, many volatile and nonvolatile components have been distinguished in baijiu [5]. Phenolic compounds were observed to remarkable affect the flavor and taste of baijiu. These phenolic compounds generally originated from the secondary metabolites of the raw materials (such as wheat or sorghum) in the fermentation process [6]. As reported in the literatures, phenolic compounds are commonly unpleasant and considered as an off flavor in baijiu, of which 4-ethylphenol (4-EP), phenol, and 4-ethylguaiacol (4-EG) often manifest medicinal, horsy, and smoky odors [7-10]. In addition, the phenolic compounds interact with oral saliva protein, resulting an unpleasant feeling of astringent [11]. Therefore, reducing the unpleasant flavor and taste of baijiu caused by phenolic compounds is important.

Phenolic compounds can interact with proteins or peptides, leading to the formation of soluble and/or insoluble complexes, which may improve the flavor and taste of baijiu [12-14]. The content of phenolic compounds in baijiu 
was obviously inhibited by lichenin, and the peptide of Ala-Lys-Arg-Ala could interact with phenolic compounds $[15,16]$. Accordingly, peptides should be an effective agent to reduce the negative feeling of phenolic compounds. However, the interaction mechanism of peptides with phenolic compounds is unclear in the baijiu system, leading to hesitance in the application of this approach. The binding between peptides and phenolic compounds is believed to be reversible and usually by non-covalent bonds, such as hydrogen bonds, hydrophobic forces, van der Waals forces, and/or electrostatic forces [17]. However, the interaction mechanism may considerably differ among phenolic compounds and peptides [18].

Collagen peptides $(\mathrm{CPs})$ are the hydrolysate of collagen that is extracted from animal skin, and they have the structure feature of Gly-X-Y repeated sequences of amino acids, in which $\mathrm{X}$ and $\mathrm{Y}$ are often proline and hydroxyproline
[19]. CPs is a natural and renewable biological macromolecule with a variety of nutritional functions and physiological properties. Besides, CPs contains $-\mathrm{NH}_{2},-\mathrm{COOH}$ and $-\mathrm{OH}$ groups, which can interact with aldehydes and phenolic compounds in baijiu [17]. In the present study, the interaction mechanism between CPs and 4-EP, phenol, guaiacol, and 4-EG was investigated in the model liquor (52\% ethanol-water solution) by using ultraviolet-visible (UV-Vis) spectroscopy, zeta potential, hydrogen nuclear magnetic spectroscopy ( ${ }^{1} \mathrm{H}$ NMR), and isothermal titration calorimetry (ITC). The content of phenolic compounds in $52 \%(v / v)$ ethanol-water solution was determined using Head Space-solid Phase Microextraction Gas Chromatography Mass Spectrometry (HS-SPME-GC-MS) at different dosages of CPs. In the real liquor, HS-SPME-GC-MS also was employed to determine the effect of CPs on volatile compounds in the light-flavor types baijiu.
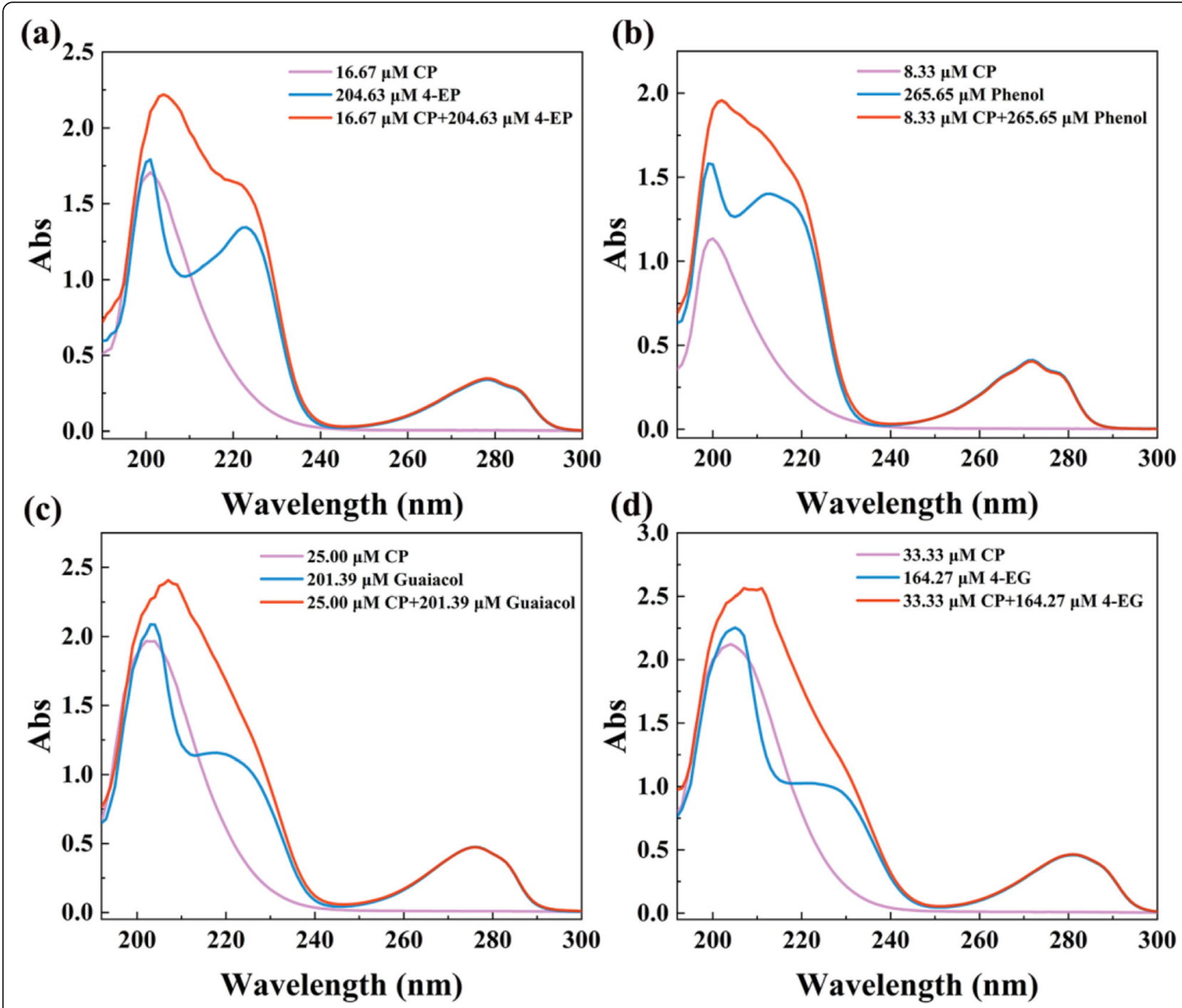

Fig. 1 UV-Vis spectrum of Collagen peptides with 4-EP (a), phenol (b), guaiacol (c), and 4-EG (d) 


\section{Materials and methods}

\subsection{Material}

CPs, a molecular weight of approximately $3000 \mathrm{Da}$, was prepared by enzymatic degradation of collagen I with the method developed in our previous work [20]. Briefly, gelatin of food grade was first dissolved in distilled water, and its concentration was controlled about $10 \%$ $(\mathrm{w} / \mathrm{v})$. Then, this gelatin solution was hydrolyzed by Alcalase enzyme for $6 \mathrm{~h}$ at $45{ }^{\circ} \mathrm{C}$. Guaiacol ('98.0\%, GC grade), 4-EP ('97.0\%, GC grade), and 4-EG ('98\%, GC grade) were purchased from Tokyo Chemical Industry (Shanghai, China), and phenol ( $\geq 98 \%$, GC grade) was obtained from Aladdin (Shanghai, China). Ethanol (99.9\%, HPLC grade) was purchased from Chron Chemical Co, Ltd (Chengdu, China). DMSO-d6 was purchased from Sigma (St. Louis, MO, USA). Light-flavor types baijiu was puchased from Zuixiantan Liquor Co., Ltd.( Sichuan, China).

\subsection{UV-Vis measurements}

The UV-Vis spectra of CPs, four phenolic compounds, and their mixtures in $52 \%$ ethanol-water solution were recorded using UV-1800 BPC spectrophotometer (Mapada, Shanghai, China) in the wavelength range of 190-350 nm. [21].

\subsection{Zeta potential determination}

The zeta potential of CPs in $52 \%$ ethanol-water solution with and without 4-EP, phenol, guaiacol, and 4-EG were measured by the zeta instrument (Nano Brook Omni, Brookhaven, USA) [22].
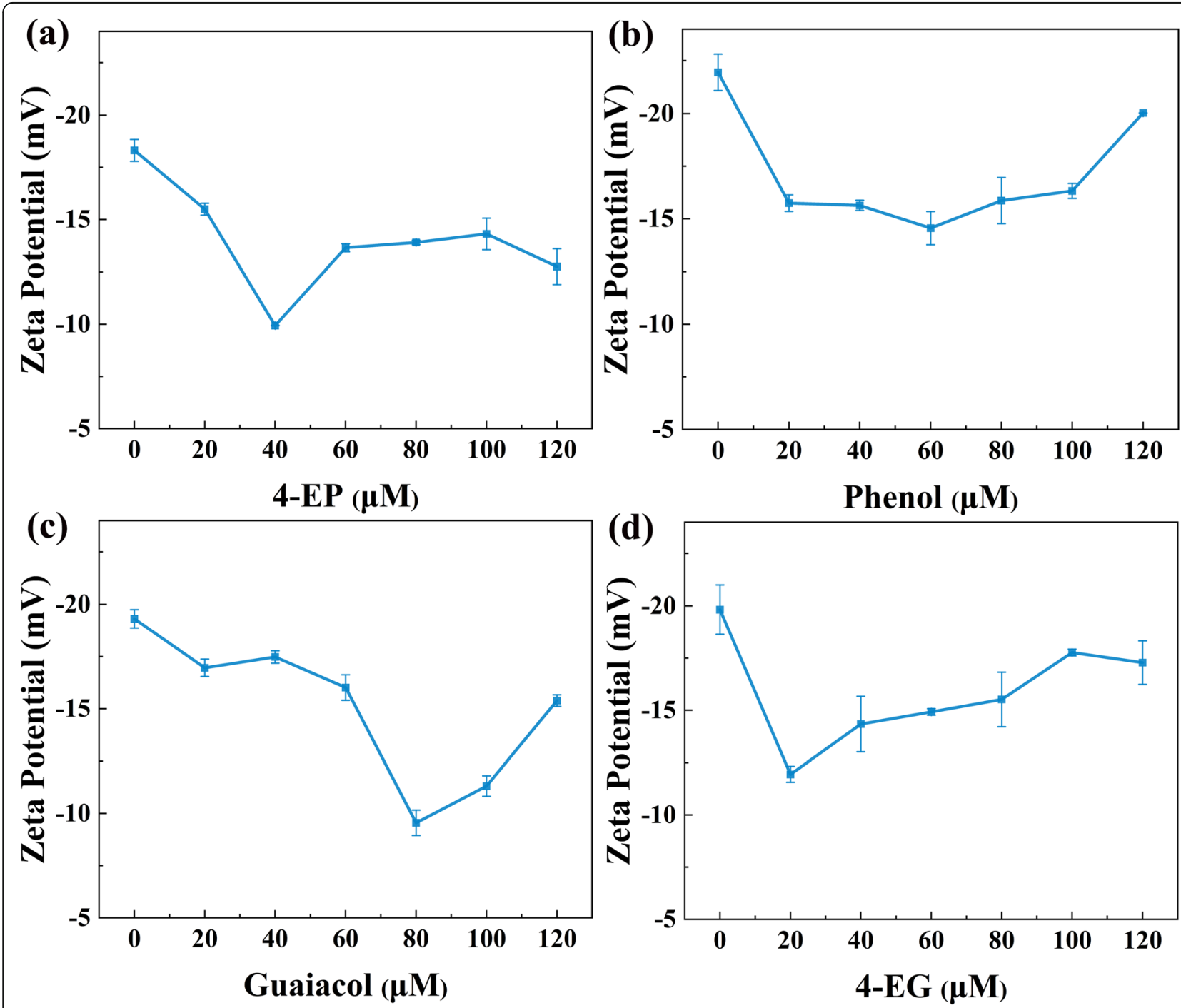

Fig. 2 Zeta potential changes in Collagen peptides in the presence of different concentrations of 4-EP (a), phenol (b), guaiacol (c), and 4-EG (d) 


\section{$2.4{ }^{1} \mathrm{H}$ NMR spectroscopy analysis}

${ }^{1} \mathrm{H}$ NMR measurements were performed on Bruker Avance AV II-600 MHz spectroscopy (Bruker, Inc., Sweden). 4-EP, phenol, guaiacol, and 4-EG were prepared in DMSO-d6 with a concentration of $300 \mathrm{mmol} / \mathrm{L}$. The molar ratio of CPs to 4-EP, phenol, and guaiacol were set as 1:300, while that to 4 -EG was set as 1:100. The ${ }^{1} \mathrm{H}$ NMR spectra of the phenolic compounds after being mixed with CPs were recorded and determined as a control [16].

\subsection{ITC detection}

ITC (MicroCal iTC200, Malvern, UK) detections were conducted to determine the affinity constants and thermodynamic parameters of the interaction between CPs and phenolic compounds. All reagents (CPs and phenolic compounds) were dissolved in $52 \%$ ethanolwater solution and centrifuged at $12,000 \mathrm{rpm}$ for $30 \mathrm{~min}$. The CPs solution was titrated into the sample cell of 4-EP, phenol, guaiacol, and 4-EG as a sequence of 20 injections of $2 \mu \mathrm{L}$ aliquots at $30{ }^{\circ} \mathrm{C}$, and the integrated binding thermograms were obtained on Origin software equipped with the instrument [23, 24].

\subsection{Solid-phase microextraction (SPME)}

Ethanol-water solution ( $52 \% \mathrm{~V} / \mathrm{V})$ was prepared as a simulated baijiu sample. 4-EP, phenol, guaiacol, and 4-EG were dissolved in this solution, and their concentrations were $1.28,0.38,0.38$, and $1.54 \mathrm{mg} / \mathrm{L}$, respectively. Then, a CPs solution was respectively added to model solution containing phenolic compounds and light-flavor types baijiu (real liquor), and attained the desired CPs concentrations of $0.00,2.00,20.00$, and $200.00 \mathrm{mg} / \mathrm{L}$, respectively [15].

For SPME, an automatic headspace sampling system with a $75 \mu \mathrm{m}$ CAR/PDMS fiber (Supelco, Inc., Bellefonte, PA, USA) was used for analyte solution. Eight $\mathrm{mL}$ of the sample with $10 \mu \mathrm{L}$ internal standard (methyl n-

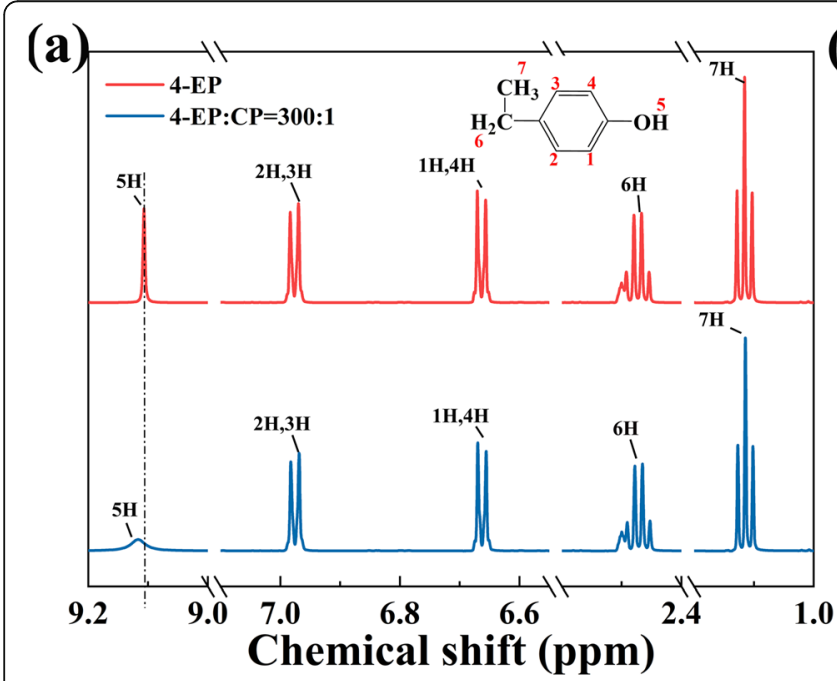

(b)

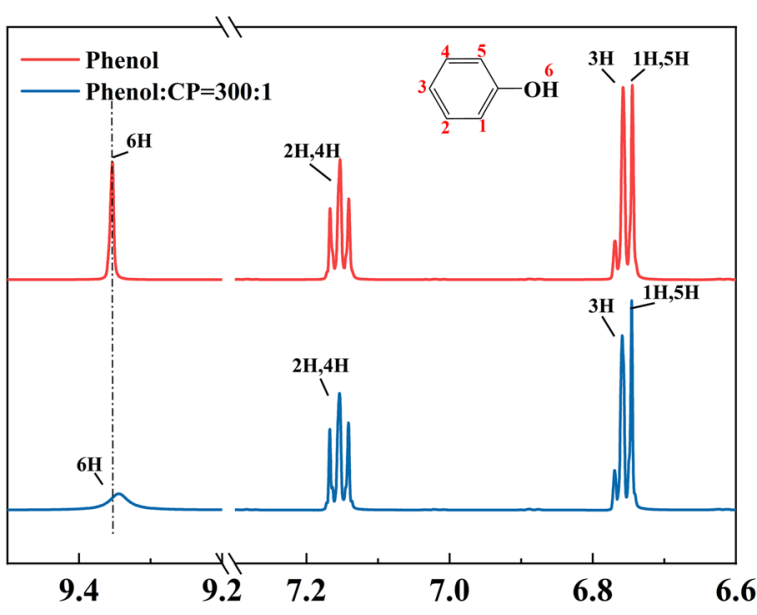

(c)

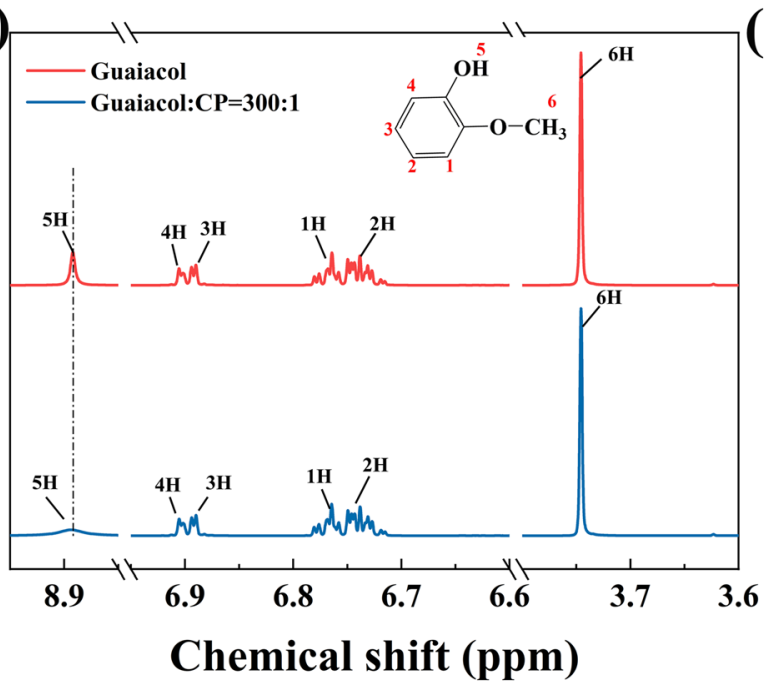

(d)

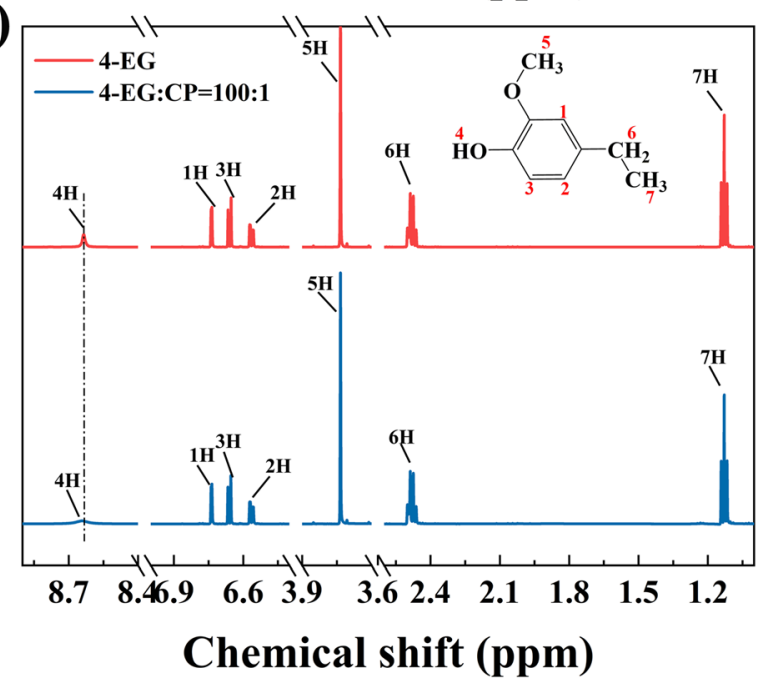

Fig. $3^{1} \mathrm{H}$ NMR spectra of CPs with phenolic compounds 4-EP (a), phenol (b), guaiacol (c), and 4-EG (d) 
octanoate, $75.00 \mathrm{mg} / \mathrm{L}$ in ethanol) was placed into a 20 $\mathrm{mL}$ headspace bottle. The sample was equilibrated at $35{ }^{\circ} \mathrm{C}$ for $10 \mathrm{~min}$, and the extraction of volatile components was performed for $45 \mathrm{~min}$ at the same temperature under stirring $(500 \mathrm{rpm})$. The experiment was repeated three times in each sample [16].

\subsection{Gas chromatography-mass spectrometry (GC-MS) analysis}

GC-MS analysis was performed on a TRACE 1300 gas chromatograph equipped with a TSQ 9000 triple quadrupole mass spectrometer (Thermo Scientific, UK). The fused silica capillaries (VF-WAXms $30 \mathrm{~m} \times 0.25 \mathrm{~mm} \times 0.25 \mu \mathrm{m}$, Agilent, Santa Clara, CA, USA) was employed as separation column, and helium was used as the carrier gas with flow rate of $5 \mathrm{~mL} / \mathrm{min}$. For the $\mathrm{GC}$ conditions, the injector temperature was maintained at $270{ }^{\circ} \mathrm{C}$. The oven temperature was started at $40{ }^{\circ} \mathrm{C}$, held for $5 \mathrm{~min}$, and then raised to $100{ }^{\circ} \mathrm{C}$ at $4{ }^{\circ} \mathrm{C} / \mathrm{min}$. It was further increased to $230{ }^{\circ} \mathrm{C}$ at $6{ }^{\circ} \mathrm{C} / \mathrm{min}$ and held for $10 \mathrm{~min}$. For the MS conditions, electron ionization mode was used with $70 \mathrm{eV}$ ionization energy. The ion-source and transfer line temperature were set as 300 , and $250{ }^{\circ} \mathrm{C}$, respectively. The scanning range was $\mathrm{m} / \mathrm{z} 35-400$.

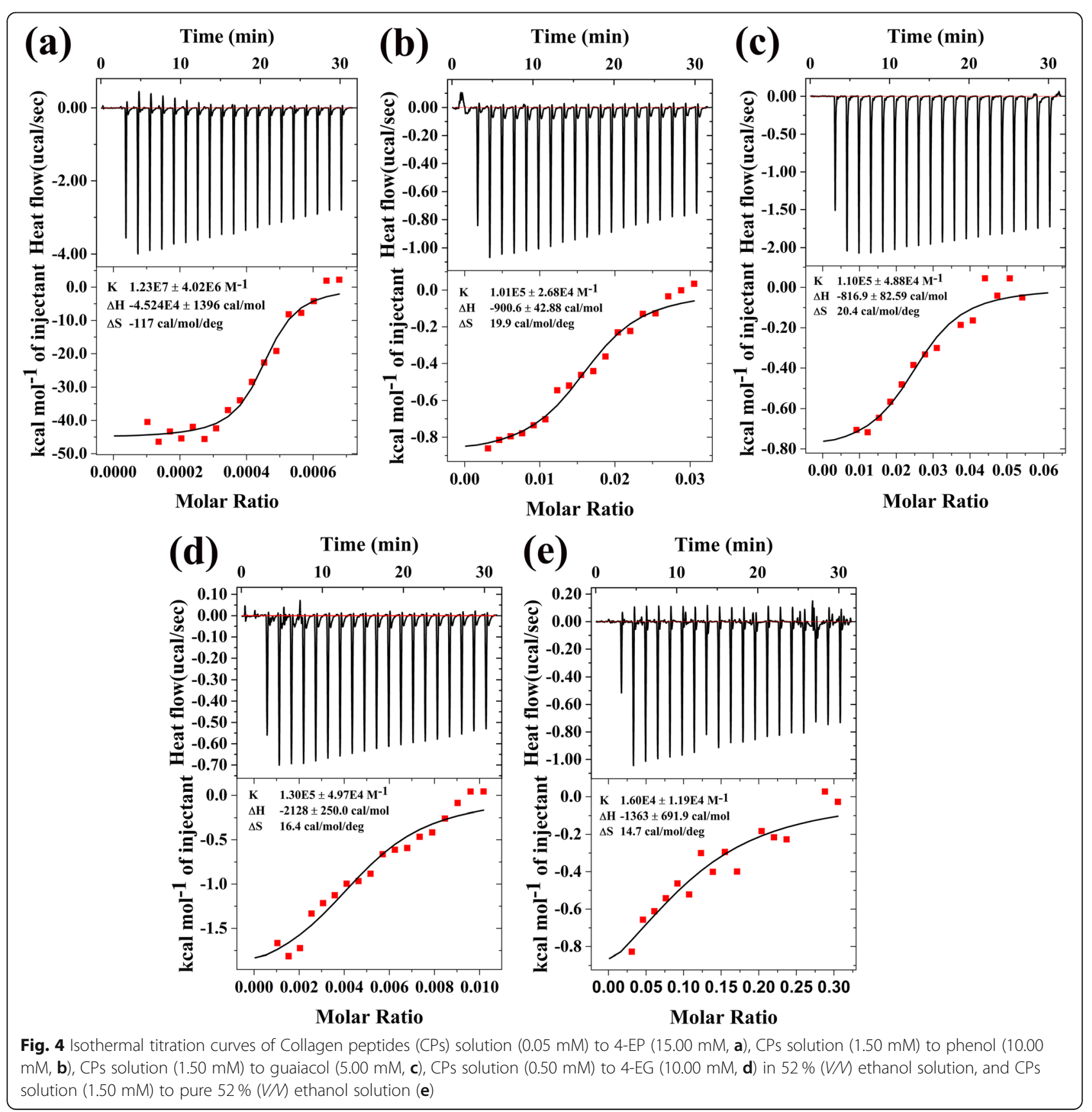


Table 1 Thermal parameters of collagen peptides reacted with phenolic compounds in $52 \%$ ethanol-water solution

\begin{tabular}{|c|c|c|c|c|c|}
\hline run & & $K_{D}\left(M^{-1}\right)$ & $\Delta \mathrm{H}(\mathrm{KJ} / \mathrm{mol})$ & $\mathrm{T} \Delta \mathrm{S}(\mathrm{KJ} / \mathrm{mol})$ & $\Delta \mathrm{G}(\mathrm{KJ} / \mathrm{mol})$ \\
\hline \multirow[t]{3}{*}{$\mathrm{CPS} \rightarrow 4-\mathrm{EP}$} & $\mathrm{n} 1$ & $(12.3 \pm 4.02) \times 10^{6}$ & $-(1.89 \pm 0.06) \times 10^{2}$ & $-1.48 \times 10^{2}$ & -41.00 \\
\hline & n2 & $(1.55 \pm 0.84) \times 10^{6}$ & $-(3.19 \pm 0.47) \times 10^{2}$ & $-2.83 \times 10^{2}$ & -36.00 \\
\hline & n3 & $(1.81 \pm 0.48) \times 10^{6}$ & $-(19.35 \pm 1.28) \times 10^{2}$ & $-19.03 \times 10^{2}$ & -32.00 \\
\hline \multirow[t]{3}{*}{$\mathrm{CPs} \rightarrow$ phenol } & $\mathrm{n} 1$ & $(0.13 \pm 0.10) \times 10^{5}$ & $-4.28 \pm 4.23$ & 19.66 & -23.94 \\
\hline & n2 & $(1.16 \pm 0.99) \times 10^{5}$ & $-10.27 \pm 2.52$ & 19.16 & -29.43 \\
\hline & n3 & $(1.01 \pm 0.27) \times 10^{5}$ & $-3.77 \pm 0.18$ & 25.25 & -29.02 \\
\hline \multirow[t]{3}{*}{$\mathrm{CPs} \rightarrow$ guaiacol } & $\mathrm{n} 1$ & $(1.10 \pm 0.49) \times 10^{5}$ & $-3.42 \pm 0.36$ & 25.88 & -29.30 \\
\hline & n2 & $(1.96 \pm 0.66) \times 10^{5}$ & $-1.72 \pm 0.08$ & 29.05 & -30.77 \\
\hline & n3 & $(1.15 \pm 0.42) \times 10^{5}$ & $-2.58 \pm 0.16$ & 26.77 & -29.35 \\
\hline \multirow[t]{3}{*}{$\mathrm{CPs} \rightarrow 4-\mathrm{EG}$} & $\mathrm{n} 1$ & $(1.30 \pm 0.50) \times 10^{5}$ & $-8.91 \pm 1.05$ & 20.81 & -29.72 \\
\hline & $\mathrm{n} 2$ & $(1.69 \pm 0.62) \times 10^{5}$ & $-13.36 \pm 1.22$ & 17.00 & -30.36 \\
\hline & n3 & $(2.10 \pm 0.59) \times 10^{5}$ & $-20.43 \pm 1.30$ & 10.48 & -30.91 \\
\hline
\end{tabular}

\subsection{Statistics}

All measurements were repeated at least three times. The results presented in the tables were expressed as means \pm standard deviation. The significance of differences was determined using one-way ANOVA, and the level of significance was $P<0.05$.

\section{Results and discussion}

\subsection{The Interaction between CPs and phenolic} compounds in the ethanol-water solution

\subsubsection{UV-Vis spectroscopy measurements}

The effect of CPs on the absorption spectra of 4-EP, phenol, guaiacol, and 4-EG was recorded by UV-vis spectroscopy, as shown in Fig. 1. The CPs generally exhibited only one absorption peak near $200 \mathrm{~nm}$, which represented the change in CPs backbone $[25,26]$. Meanwhile, three absorption peaks in 4-EP, phenol, guaiacol, and 4-EG, respectively. The peaks around 200 and $220 \mathrm{~nm}$ could be attributed to the $\pi-\pi^{*}$ transitions of $\mathrm{C}=\mathrm{C}$ of the benzene ring, while the peaks around $280 \mathrm{~nm}$ corresponded to the $\pi-\pi *$ transitions of the benzene ring [27]. When 4-EG interacted with CPs, the absorption peak around $200 \mathrm{~nm}$ was redshifted, while the peak around $220 \mathrm{~nm}$ was almost

Table 2 Effect of CPs on the content of phenolic compounds in the volatile components in $52 \%$ ethanol-water solution as determined by HS-SPME-GC-MS

\begin{tabular}{lllll}
\hline $\begin{array}{l}\text { aroma } \\
\text { compound/ } \\
\text { ( } \boldsymbol{\mu g} / \mathbf{L})\end{array}$ & \multicolumn{4}{l}{ Collagen peptides } \\
\cline { 2 - 5 } & $\mathbf{0 . 0 0} \mathbf{~ m g} / \mathbf{L}$ & $\mathbf{2 . 0 0} \mathbf{~ m g / L}$ & $\mathbf{2 0 . 0 0} \mathbf{~ m g / L}$ & $\mathbf{2 0 0 . 0 0} \mathbf{~ m g} / \mathbf{L}$ \\
\hline $4-E P$ & $2.54 \pm 0.30 \mathrm{a}$ & $1.78 \pm 0.30 \mathrm{ab}$ & $2.02 \pm 0.47 \mathrm{ab}$ & $2.06 \pm 0.06 \mathrm{~b}$ \\
phenol & $4.72 \pm 0.65 \mathrm{a}$ & $2.63 \pm 0.48 \mathrm{~b}$ & $3.42 \pm 0.58 \mathrm{~b}$ & $3.29 \pm 0.09 \mathrm{~b}$ \\
guaiacol & $3.57 \pm 0.32 \mathrm{a}$ & $2.57 \pm 0.33 \mathrm{~b}$ & $2.82 \pm 0.14 \mathrm{~b}$ & $2.94 \pm 0.27 \mathrm{~b}$ \\
4-EG & $23.20 \pm 0.64 \mathrm{a}$ & $18.88 \pm 2.51 \mathrm{a}$ & $20.20 \pm 4.54 \mathrm{a}$ & $20.06 \pm 0.82 \mathrm{a}$ \\
\hline
\end{tabular}

For same line, different letters $(a, a b, b)$ indicate significant differences among samples with different concentrations of collagen peptides $(p<0.05)$, in which same letters represent no significantly different disappeared. The change of the absorption peaks of CPs \& phenol, CPs \& guaiacol, CPs \& 4-EG in model solution were similar to that of CPs \& 4-EP. Therefore, the CPs definitely combined with phenolic compounds. However, the absorption peaks of phenolic compounds around 280 $\mathrm{nm}$ were almost unchanged, suggesting that the CPs have no effect on the $\pi-\pi^{*}$ transitions of the benzene ring.

The interaction forces between protein and small molecule include hydrogen bond, van der Waals force, hydrophobic force, and electrostatic force [28]. According to previous researches, CPs could form a complex with phenolic compounds by hydrophobic bonds due to their hydrophobicity [29]. Likewise, CPs and phenolic compounds could be combined by hydrogen bonds through phenolic hydroxyls [17].

\subsubsection{Zeta-potential measurement}

The surface of CPs carries charges due to its polar and nonpolar groups, such as $-\mathrm{NH}^{3+}$ and $-\mathrm{COO}^{-}[30,31]$. The zeta potential could provide information about the surface charge of CPs. Moreover, the absolute value of the zeta potential (A-ZP) of protein was correlated to its hydrophobicity [32].

The zeta potential of the CPs system after adding different concentrations of phenolic compounds was measured. As shown in Fig. 2a and d, the A-ZP of CPs decreased when a low concentration of phenolic compounds was added. However, the A-ZP increased with the increase of the phenolic compounds concentration. The decrease in A-ZP indicated that a complex was formed between CPs and phenolic compounds, and this finding was similar with the result of Pdziwiatr-Werbicka et al. [33]. When the concentration of phenolic compounds was continued to be increased, the interaction with CPs tended to be saturated [34]. Further increasing the concentration gradually increased the A-ZP because the phenolic 
compounds were negatively charged due to the release of proton [35]. The results of zeta potential determination further indicated that CPs could bond with phenolic compounds.

\section{$3.2{ }^{1} \mathrm{H}$ NMR analysis}

The ${ }^{1} \mathrm{H}$ NMR spectra of four phenolic compounds before and after interacting with CPs are presented in Fig. 3. The hydrogen peaks of the phenolic hydroxyl of these compounds almost disappeared after CPs interaction, suggesting the possibility that hydrogen bonds were formed between phenolic compounds and CPs. However, the hydrogen bond forming ability in CPs considerably differ among these four phenolic compounds. For the CPs \& 4EP (Fig. 3(a)), comparing the ${ }^{1} \mathrm{H}$ NMR spectrum of the 4$\mathrm{EP}$ to the 4-EP in the presence of CPs, the chemical shift corresponding to the proton of phenolic hydroxyl moved from 9.11 to $9.12 \mathrm{ppm}$. It is an obvious change according literature [36]. For the phenol (Fig. 3(b)), the addition of CPs made the chemical shift of proton in the phenol hydroxyl group moved from 9.35 to $9.34 \mathrm{ppm}$. These facts suggested that 4-EP and phenol should be interacted with CPs through hydrogen bonds. However, for the guaiacol
(Fig. 3(c)) and 4-EG (Fig. 3(d)), there is no significant change in the chemical shift of proton after CPs added. Combined with the UV-vis analysis results (Fig. 1), it is reasonable to believe that guaiacol and 4-EG should be interacted with CPs by the hydrophobic bonds.

As shown in the molecular structure, the phenolic hydroxyl of 4-EP was located at the para of the substituent group, and no substituent group was found for phenol. Meanwhile, the phenolic hydroxyls of guaiacol and 4-EG were located at the ortho of the substituent group, and intramolecular hydrogen bonds may be formed [37], resulting in signal reduction and the broadening of the hydrogen of phenolic hydroxyl. Therefore, 4-EP and phenol could easily to form hydrogen bonds with CPs. However, organic solvents, especially ethanol, could inhibit the interaction between CPs and phenolic compounds, and the hydrogen bonds are easily destroyed compared with those in aqueous solution [17].

\subsection{Thermodynamic parameters between CPs and} phenolic compounds in the ethanol-water solution by ITC ITC investigation was conducted to further understand the interaction mechanism between CPs and

Table 3 Effect of CPs on the content of volatile compounds in light-flavor types baijiu as determined by HS-SPME-GC-MS

\begin{tabular}{|c|c|c|c|c|c|}
\hline Volatile compounds & $\begin{array}{l}\text { Control } \\
\mu \mathrm{g} / \mathrm{L}\end{array}$ & $\begin{array}{l}\text { Collagen peptides } \\
200.00 \mathrm{mg} / \mathrm{L}\end{array}$ & Volatile compounds & $\begin{array}{l}\text { Control } \\
\mu \mathrm{g} / \mathrm{L}\end{array}$ & $\begin{array}{l}\text { Collagen peptides } \\
200.00 \mathrm{mg} / \mathrm{L}\end{array}$ \\
\hline Ethyl propionate & $125.36 \pm 26.21 a$ & $79.15 \pm 14.89 b$ & Phenethyl acetate & $280.44 \pm 6.70 a$ & $237.90 \pm 3.24 c$ \\
\hline Ethyl isobutyrate & $19.58 \pm 1.91 a$ & $14.47 \pm 0.67 b$ & Ethyl laurate & $459.16 \pm 47.46 a$ & $402.72 \pm 43.09 b$ \\
\hline Isobutyl acetate & $20.12 \pm 1.31 a$ & $15.83 \pm 3.90 a$ & Ethyl hydrocinnamate & $37.38 \pm 2.29 a$ & $33.71 \pm 1.38 b$ \\
\hline Ethyl butyrate & $256.61 \pm 17.60 a$ & $240.86 \pm 10.02 \mathrm{a}$ & Ethyl myristate & $109.01 \pm 9.39 a$ & $99.33 \pm 11.30 a$ \\
\hline Ethyl 2-methylbutyrate & $10.60 \pm 0.44 a$ & $10.12 \pm 1.99 a$ & Ethyl palmitate & $112.18 \pm 6.26 a$ & $95.29 \pm 12.50 a$ \\
\hline Ethyl isovalerate & $33.45 \pm 3.70 a$ & $25.86 \pm 6.95 a$ & 2-Butanol & $17.51 \pm 1.83 a$ & $11.76 \pm 2.83 b$ \\
\hline Isoamyl acetate & $623.84 \pm 37.76 a$ & $590.05 \pm 31.99 a$ & 2-Methyl-1-propanol & $93.23 \pm 9.23 a$ & $64.01 \pm 14.31 b$ \\
\hline Ethyl pentanoate & $283.60 \pm 13.13 a$ & $251.01 \pm 61.76 a$ & 3-Methyl-1-butanol & $1120.14 \pm 102.90 a$ & $885.42 \pm 3.12 b$ \\
\hline Isoamyl propionate & $16.24 \pm 2.47 a$ & $15.93 \pm 3.06 a$ & Hexyl alcohol & $74.43 \pm 9.00 a$ & $67.65 \pm 0.36 a$ \\
\hline Ethyl caproate & $1326.29 \pm 17.43 a$ & $1250.90 \pm 334.27 a$ & 1-nonanol & $48.77 \pm 0.96 a$ & $44.99 \pm 10.93 a$ \\
\hline Isoamyl butyrate & $22.59 \pm 3.27 a$ & $22.84 \pm 2.58 a$ & 1-Decanol & $37.28 \pm 1.45 a$ & $32.46 \pm 5.77 b$ \\
\hline Hexyl acetate & $36.81 \pm 0.42 a$ & $28.32 \pm 5.93 b$ & Phenethyl alcohol & $113.78 \pm 0.30 a$ & $83.12 \pm 1.22 c$ \\
\hline Ethyl heptanoate & $106.29 \pm 0.50 a$ & $102.59 \pm 30.28 a$ & Hexanal & $15.54 \pm 3.46 a$ & $16.03 \pm 4.17 a$ \\
\hline Ethyl lactate & $41.76 \pm 3.63 a$ & $31.45 \pm 4.28 b$ & Heptaldehyde & $14.85 \pm 0.89 a$ & $12.58 \pm 2.71 b$ \\
\hline Ethyl caprylate & $3146.73 \pm 9.13 a$ & $2757.36 \pm 483.39 a$ & 3-Furaldehyde & $270.96 \pm 7.94 a$ & $257.19 \pm 0.80 a$ \\
\hline Isopentyl hexanoate & $17.28 \pm 0.04 a$ & $15.78 \pm 3.18 a$ & Decanal & $9.20 \pm 0.21 a$ & $8.27 \pm 1.21 \mathrm{a}$ \\
\hline Octyl acetate & $19.67 \pm 0.29 a$ & $19.47 \pm 5.73 a$ & Benzaldehyde & $240.92 \pm 0.79 a$ & $200.08 \pm 49.94 a$ \\
\hline Ethyl nonanoate & $78.13 \pm 1.92 \mathrm{a}$ & $84.58 \pm 21.19 a$ & 2-Pentylfuran & $9.88 \pm 1.52 \mathrm{a}$ & $13.22 \pm 4.36 a$ \\
\hline Ethyl benzoate & $43.50 \pm 0.45 a$ & $40.68 \pm 1.66 a$ & 1,1,3-Triethoxypropane & $10.30 \pm 0.68 a$ & $7.76 \pm 1.21 b$ \\
\hline Diethyl succinate & $49.23 \pm 1.30 a$ & $40.99 \pm 0.10 c$ & Decanoic acid & $17.71 \pm 2.26 a$ & $15.18 \pm 5.46 a$ \\
\hline Ethyl undecanoate & $11.82 \pm 0.72 \mathrm{a}$ & $11.14 \pm 1.38 a$ & Acetophenone & $25.89 \pm 0.36 a$ & $22.29 \pm 0.12 b$ \\
\hline Ethyl phenylacetate & $34.18 \pm 0.30 a$ & $31.73 \pm 2.26 a$ & 2,4-Di-tert-butylphenol & $2.00 \pm 0.02 \mathrm{a}$ & $1.39 \pm 0.32 b$ \\
\hline
\end{tabular}

For same line, different letters $(a, b, c)$ indicate significant differences between samples with different concentrations of collagen peptides $(p<0.05)$, in which same letters represent no significantly different 
the four phenolic compounds in $52 \%(v / v)$ ethanol solution system. The isotherms obtained using a CPs solution respectively titrated into 4-EP, phenol, guaiacol, and 4-EG at $30{ }^{\circ} \mathrm{C}$ are described in Fig. 4 (a-d). For comparison, the isotherm of the CPs solution titrated into pure $52 \%(v / v)$ ethanol solution was also obtained, as shown in Fig. 4e. A reaction between CPs and phenolic compounds obviously occurred, and it was an exothermic process because of the downward heat-burst curves presented [38].

The thermodynamic parameters of CPs that reacted with the four phenolic compounds in $52 \%(v / v)$ ethanol solution are summarized in Table 1 , where $n$ is the number of samples, $K_{D}$ is the binding constant, $\Delta \mathrm{H}$ is the enthalpy change, $\Delta \mathrm{S}$ is the entropy change, and $\Delta G$ is the free energy. The reaction of CPs with phenolic compounds was generally a spontaneous process due to $\Delta G<0$. The comparison between the absolute value of $\Delta \mathrm{H}(|\Delta \mathrm{H}|)$ and $-\mathrm{T} \Delta \mathrm{S}(|-\mathrm{T} \Delta \mathrm{S}|)$ could be used to further determine the reaction mechanism of CPs with phenolic compounds. In general, hydrogen bond interaction occurs if $|\Delta \mathrm{H}|$ is higher than $|-\mathrm{T} \Delta \mathrm{S}|$; otherwise, it should a hydrophobic bond interaction [39, 40]. In case of 4-EP, the major binding mechanism was hydrogen bonds $(|\Delta \mathrm{H}|>|-\mathrm{T} \Delta \mathrm{S}|)$, which is related to the carbonyl group of CPs, the phenolic hydroxyl group of 4-EP. as confirmed by the analysis of UV-vis and ${ }^{1} \mathrm{H}$ NMR. For guaiacol and 4-EG, hydrophobic bonding was the main interaction mechanism because $|\Delta \mathrm{H}|$ was smaller than $|-\mathrm{T} \Delta \mathrm{S}|$. These findings were consistent with the ${ }^{1} \mathrm{H}$ NMR determination (Fig. 3). However, $|\Delta \mathrm{H}|$ was smaller than $|-\mathrm{T} \Delta \mathrm{S}|$ for phenol, but the ${ }^{1} \mathrm{H}$ NMR determination indicated that hydrogen bonds took part in the reaction. Therefore, the ITC and ${ }^{1} \mathrm{H}$ NMR investigation results suggested that 4EP mainly hydrogen bonded with CPs, while guaiacol and 4-EG mainly hydrophobic bonded with CPs. Meanwhile, both bonds were involved in phenol, and this finding was similar with the result of Zhang et al. [15].

\subsection{The content of phenolic compounds in the ethanol- water solution}

According literatures, HS-SPME-GC-MS is a common approach to analyze the phenolic compounds in baijiu $[15,16]$. Hence, the content of four phenolic compounds in the volatile components after adding different dosages of CPs were measured using HS-SPME-GC-MS, as listed in Table 2. The content of phenolic compounds was estimated to reduce by $13.53-44.28 \%$. Therefore, the result further confirmed that CPs can interact with phenolic compounds, which would definitely reduce their unpleasant feeling in baijiu.

\subsection{The content of volatile compounds in light-flavor types baijiu}

A sum of 44 volatile compounds were identified in lightflavor types baijiu by HS-SPME-GC-MS, including 27 esters, 7 alcohols, 5 aldehydes, 1 acid, 1 phenolic compound, 1 ketone, and 2 other compounds. Addition of $\mathrm{CPs}$ to the light-flavor types baijiu results in reduced contents of volatile compounds (Table 3). Therefore, $\mathrm{CPs}$ changed the whole aroma profile of baijiu. Among them, the content of phenolic compounds (2,4-Di-tertbutylphenol) was obviously declined, and it is indirectly confirmed the interaction between CPs and the phenolic compounds in baijiu.

\section{Conclusions}

In summary, the investigations of UV-Vis, zeta potential, and ${ }^{1} \mathrm{H}$-NMR spectroscopy analysis revealed the existence of intermolecular interactions of CPs with 4-EP, phenol, guaiacol, and 4-EG in the ethanol-water solution. Combined with ITC determination, the results showed that 4-EP mainly hydrogen bonded with CPs, and guaiacol and 4-EG mainly hydrophobic bonded with CPs. Meanwhile, hydrogen and hydrophobic bonds were all involved for the interaction of CPs and phenol. In addition, HS-SMPE-GC-MS determination indicated that the addition of CPs could obviously reduce the content of phenolic compounds in $52 \%$ ethanol-water solution. In the real liquor, the HS-SPME-GC-MS determination showed that CPs also reduced the content of volatile compounds of light-flavor types baijiu, which is possible applicated to real liquor preparation.

\section{Acknowledgements}

We thank Dr. Xiu He at college of biomass science and engineering, Sichuan University, for the assistance involved in the experimental equipment. We acknowledge the financial support provided by the National Key R \& D Program of China (2017YFB0308500)

\section{Authors' contributions}

Xian Liu: Methodology, Investigation, Data curation, Writing - Original draft; Xia Li: Conceptualization, Writing - Review \& Editing; Zhangjun Huang: Investigation; Xuepin Liao: Validation, Writing - Review \& Editing; Bi Shi: Writing - Review \& Editing. The author(s) read and approved the final manuscript.

\section{Funding}

The National Key R \& D Program of China (2017YFB0308500).

Availability of data and materials

Not applicable.

\section{Declarations}

\section{Competing interests}

The authors declare no competing financial interest.

\section{Author details}

${ }^{1}$ Department of Biomass Science and Engineering, Sichuan University, 610065 Chengdu, China. ${ }^{2}$ The Key Laboratory of Leather Chemistry and 
Engineering of Ministry of Education, Sichuan University, 610065 Chengdu, China. ${ }^{3}$ National Engineering Research Centre of Clean Technology in Leather Industry, Sichuan University, 610065 Chengdu, PR China.

Received: 12 March 2021 Accepted: 8 June 2021

Published online: 15 September 2021

\section{References}

1. Huo JY, Luo XL, Huang MQ, Wu JH, Zhang JL, Liu XX, Li HH, Sun XT. Identification and Antioxidant Activity of a Novel Peptide from Baijiu. Int J Pept Res Ther. 2020:26:1199-210.

2. Wei Y, Zou W, Shen $\mathrm{CH}$, Yang JG. Basic flavor types and component characteristics of Chinese traditional liquors: A review. J Food Sci. 2020;85: 4096-107.

3. He YX, Liu ZP, Qian M, Yu XW, Xu Y, Chen S. Unraveling the chemosensory characteristics of strong-aroma type Baijiu from different regions using comprehensive two-dimensional gas chromatography-time-of-flight mass spectrometry and descriptive sensory analysis. Food Chem. 2020;331:127335.

4. Hong JX, Tian WJ, Zhao DR. Research progress of trace components in sesame-aroma type of baijiu. Food Res Int. 2020;137:109695.

5. Jia W, Fan ZB, Du A, Li YL, Zhang R, Shi QY, Shi L, Chu XG. Recent advances in Baijiu analysis by chromatography based technology-A review. Food Chem. 2020;324:126899.

6. Peng QR, Dong $R$, Xun SY, Yang M, Feng YY, Sun D, Geng PL. Determination of volatile phenols in Chinese liquors by high-performance liquid chromatography associated with $\beta$-cyclodextrin and a protective barrier layer. Flavour Fragrance Journal. 2013;28:137-43.

7. Caboni P, Sarais G, Cabras M, Angioni A. Determination of 4-Ethylphenol and 4-Ethylguaiacol in Wines by LC-MS-MS and HPLC-DAD-Fluorescence. Agric Food Chem. 2007;55:7288-93.

8. Larcher R, Nicolini G, Puecher C, Bertoldi D, Moser S, Favaro G Determination of volatile phenols in wine using high-performance liquid chromatography with a coulometric array detector. Anal Chim Acta. 2007; 582:55-60

9. Xu Y. Determination of Odor Thresholds of Volatile Aroma Compounds in Baijiu by A Forced-choice Ascending Concentration Series Method of Limits[J]. Liquor Making. 2011;38:80-4

10. Zhu H, Yang T, Hao ZB, Yao P, Wu J, Lan CH, Liu SG, Wu XX. Effect of Phenols on Liquor Flavor and Control Strategy of Phenols in Baijiu[J]. 40: Science and Technology of Food Industry; 2019. pp. 361-7.

11. Huang $\mathrm{R}, \mathrm{Xu} \mathrm{CM}$. An overview of the perception and mitigation of astringency associated with phenolic compounds. Comprehensive Reviews in Food Science Food Safety. 2021;20:1036-74.

12. Czubinski J, Feder S. Lupin seeds storage protein composition and their interactions with native flavonoids. J Sci Food Agric. 2019:99:4011-8.

13. Silva FGDE, Miralles B, Hernández-Ledesma B, Amigo L, Iglesias AH, Reyes FGR, Netto FM. Influence of Protein-Phenolic Complex on the Antioxidant Capacity of Flaxseed (Linum usitatissimum L.) Products. J Agric Food Chem. 2017;65:800-9.

14. Alu'datt MH, Rababah T, Ereifej K, Brewer S, Alli I. Phenolic-protein interactions in oilseed protein isolates. Food Res Int. 2013;52:178-84.

15. Zhang $R$, Wu Q, Xu Y. Lichenysin, a Cyclooctapeptide Occurring in Chinese Liquor Jiannanchun Reduced the Headspace Concentration of Phenolic OffFlavors via Hydrogen-Bond Interactions. J Agric Food Chem. 2014;62:8302-7.

16. Huang MQ, Huo JY, Wu JH, Zhao MM, Zheng FP, Sun JY, Sun XT, Li HH. Interactions between $\mathrm{p}$-Cresol and Ala-Lys-Arg-Ala (AKRA) from SesameFlavor-Type Baijiu. Langmuir. 2018;34:12549-59.

17. Shi B, Geng Y. Chapter two. plant polyphenol. 7-03-008045-9. Beijing: Science Press; 2000. pp. 67-91.

18. Garcia-Estevez I, Ramos-Pineda AM, Escribano-Ballon MT. Interactions between wine phenolic compounds and human saliva in astringency perception. Food Function. 2018:9:1294-309.

19. Wei WY, Li DF, Cai XD, Liu Z, Bai ZT, Xiao JX. Peptide Probes with Aromatic Residues Tyr and Phe at the X Position Show High Specificity for Targeting Denatured Collagen in Tissues. ACS Omega. 2020;5:33075-82.

20. Li X, Zeng WC, Zhu DY, Feng JL, Tian CC, Liao XP, Shi B. Investigation of collagen hydrolysate used as carbon and nitrogen source in the fermentation of Bacillus pumilus. Process Biochem. 2017;55:11-6.

21. Mirzaei S, Mobedi H, Gourabi H, Sanati MH, Khezli S, Omidian H, Ighaeie M. Enhancement of The Stability of Human Growth Hormone by Using
Tris(hydroxymethyl)aminomethane: Molecular Docking and Experimental Analysis. Cell Journal. 2020:22:406-14.

22. Mathew EN, Hurst MN, Wang BL, Murthy V, Zhang YT, DeLong RK. Interaction of Ras Binding Domain (RBD) by chemotherapeutic zinc oxide nanoparticles: Progress towards RAS pathway protein interference. Plos One. 2020;15:e0243802

23. Ersöz N, Dudak FC. The interaction between $\beta$-Lactoglobulin and allylisothiocyanate. Food Bioscience. 2020;36:100600.

24. Jia YN, Gao XD, Xue ZH, Wang YJ, Lu YP, Zhang M, Panichayupakaranant P, Chen HX. Characterization, antioxidant activities, and inhibition on aglucosidase activity of corn silk polysaccharides obtained by different extraction methods. Int J Biol Macromol. 2020;163:1640-8.

25. Ren GY, Sun H, Guo JY, Fan JL, Li G, Xu SW. Molecular mechanism of the interaction between resveratrol and trypsin via spectroscopy and molecular docking. Food \& Function, 2019,10, 3291-3302.

26. Rao ZH, Wang MA, Zhang L. Study on the Mechanism of Interaction between Cinnamaldehyde and Zein Based on Spectral Analysis Technology. Spectroscopy Spectral Analysis. 2019;39:1940-6.

27. Ning YC. Chapter eight. In: Structural Identification of Organic Compounds and Organic Spectroscopy, 7-302-00276-2. Beijing: Science Press; 2000. pp. 368-79.

28. Ren GY, Sun H, Li G, Fan JL, Wu Y, Cui GT. Molecular docking and muiltple spectroscopy investigation on the binding characteristics of aloe-emodin to pepsin. J Mol Struct. 2019;1195:369-77.

29. Emsley J. Convergent Recognition of a Triple Helical Hydrophobic Motif in Collagen. Structure. 2010;18:1-2.

30. Gholami H, Divsalar A, Abbasalipourkabir R, Ziamajidi N, Saeidifar M. The simultaneous carrier ability of natural antioxidant of astaxanthin and chemotherapeutic drug of 5 -fluorouracil by whey protein of $\beta$-lactoglobulin: spectroscopic and molecular docking study. Journal of Biomolecular Structure and Dynamics, 2020,1-13.

31. Zhao Y, Li F, Carvajal MT, Harris MT. Interactions between bovine serum albumin and alginate: An evaluation of alginate as protein carrier. J Colloid Interface Sci. 2009:332:345-53.

32. Qi BK, Li Y, Wang ZJ, Sun XN, Jiang LZ. Relationship between Surface Hydrophobicity and Zeta Potential as well as Particle Size Distribution of Soybean Protein Isolates from Different Varieties. Food Science. 2017;38:1 14-8.

33. Pdziwiatr-Werbicka E, Gorzkiewicz M, Horodecka K, Lach D, Barrios-Gumiel A, Sanchez-Nieves J, Gomez R, de la Mata FJ, Bryszewska M. PEGylation of Dendronized Gold Nanoparticles Affects Their Interaction with Thrombin and siRNA. J Phys Chem B. 2021;125:1196-206.

34. Hosainzadeh A, Gharanfoli M, Saberi MR, Chamani J. Probing the Interaction of Human Serum Albumin with Bilirubin in the Presence of Aspirin by MultiSpectroscopic, Molecular Modeling and Zeta Potential Techniques: Insight on Binary and Ternary Systems. J Biomol Struct Dyn. 2012;29:1013-50.

35. Ming Y, Chen L, Khan A, Wang H, Wang CN. Effects of tea polyphenols on physicochemical and antioxidative properties of whey protein coating. Food Sci Biotechnol. 2020;29:1655-63.

36. Kaur A, Kaur K, Banipal PK, Banipal TS. Investigations on the $\mathrm{pH}$-dependent binding of sodium valproate with bovine serum albumin: A calorimetric, spectroscopic and volumetric approach[J]. The Journal of Chemical Thermodynamics, 2020,152,106269

37. Varfolomeev MA, Nagrimanov RN, Stolov MA, Ferrando N, Lugo R, de Hemptinne JC. Guaiacol and its mixtures: New data and predictive models. Part 2: Gibbs energy of solvation. Fluid Phase Equilib. 2018;470:91-100.

38. Nandy A, Pramanik U, Mahato P, Shekhar S, Paul B. k:;Mukherjee, S. Contrasting Thermodynamics Governs the Interaction of 3-Hydroxyflavone with the N-Isoform and B-Isoform of Human Serum Albumin. Langmuir. 2020;36:8570-9

39. Saha U, Dolai M, Kumar GS. Targeting nucleic acid with a bioactive fluorophore: Insights from spectroscopic and calorimetric studies. J Mol Struct. 2020:1220:128690

40. Nakayama N, Sakashita G, Nagata T, Kobayashi N, Yoshida H, Park SY, Nariai Y, Kato H, Obayashi E, Nakayama K, Kyo S, Urano T. Nucleus AccumbensAssociated Protein 1 Binds DNA Directly through the BEN Domain in a Sequence-Specific Manner. Biomedicines. 2020;8:608

\section{Publisher's Note}

Springer Nature remains neutral with regard to jurisdictional claims in published maps and institutional affiliations. 